\title{
Management of Congenital Lobar Emphysema: The Current Challenges
}

\author{
Yasser Ali Kamal* \\ Department of Cardiothoracic Surgery, Minia University Hospital, Egypt
}

*Corresponding Author: Yasser Ali Kamal, Department of Cardiothoracic Surgery, Minia Cardiothoracic University Hospital, El-Minya El-Jadeda, Minia, Egypt, E-mail: yaser_ali_kamal@yahoo.com

\begin{abstract}
Congenital lobar emphysema (CLE) is a rare but serious developmental lung malformation. It has a wide range of clinical presentation, but commonly with life-threatening acute respiratory distress at neonatal period. Asymptomatic cases may present in late childhood or early adulthood. This malformation may associate with other congenital malformations practically of cardiac origin. Misdiagnosis on initial chest $X$ rays with pneumothorax is common with a probably fatalinsertion of intercostal tube. Early diagnosis and treatment of CLE improves outcome and reduces mortality. A controversy remains regarding diagnostic methods, and the choice of appropriate conservative or surgical treatment. This review targets the literature for the current established and controversial management issues about CLE in practice.
\end{abstract}

Abbreviations: Congenital cystic adenomatoid malformation(CCAM), Congenital heart disease(CHD), Congenital lobar emphysema(CLE), Computed tomography(CT), Magnetic resonance imaging(MRI),Patent ductusarteriosus(PDA), Pressure regulated volume controlled(PRVC), Video-assisted thoracoscopic surgery(VATS)

Keywords: Lung Malformations, Congenital Lobar Emphysema, Thoracic Surgery, Pediatric Surgery

\section{INTRODUCTION}

Development of the respiratory system begins at the $3^{\text {rd }}$ week of gestation. The developmental aberrations may result in structural abnormalities called bronchopulmonary foregut malformations that may presented at neonatal period as parenchymal abnormalities of the lung [1].Congenital lobar emphysema (CLE) is one of these rare and serious development allung malformations, occurring in 1:20,000 to1:30,000 deliveries [2], and characterized by partial obstruction of the bronchus resulting in hyperinflation of lung lobe.

It is usually unilateral with a male pre ponderance. The most commonly involved lobes are the left upper lobe (40-50\%) and the right middle lobe $(30-40 \%)$ [3, 4]. However, involvement of pulmonary segments [5], and bilateral lung involvement were reported [6].

CLE commonly presented at the neonatal period, but rare cases were reported in late childhood or early adulthood $[7,8]$. There is no uniform etiology of CLE. Up to50\% of cases have no cause, while congenital defect of cartilage presents in $25 \%$ and other causes of bronchial obstruction underlying the remaining $25 \%$ of cases [9]. There is an additional evidence for inherited factors in the etiology of congenital lobar emphysema. Roberts et al [10] described two cases of CLE involving the right upper and middle lobes in a father and son secondary to relative deficiency of the bronchial cartilage.

CLE may associate with other congenital cardiac malformations, such as patent ductusarteriosus, atrial septal defect, ventricular septal defect, total anomalous pulmonary venous return, and Tetralogy of Fallot [11].In addition, CLE may associate with double superior vena cava, horseshoe kidney [12], and polysplenia [13].

Controversy remains concerning the diagnosis and treatment of congenital lobar emphysema, with a wide variation in practice regarding its management $[14,15]$. Therefore, this review of literature highlights the established and controversial concerns about the management of CLE in the current practice of thoracic pediatric surgery. 


\section{Clinical Presentation}

Clinical presentation of CLE varies from no symptoms to severe respiratory distress [3].It may present as life threatening respiratory distress commonly within the first 6 months of life due to compression atelectasis, mediastinal shift, hypoxia, and associated hypotension [16].

Unusual presentations of CLE reported in literature. Rusakow and Khare [17] described radio graphically occult CLE presented as unexplained neonatal tachypnea. Arnaud et al [18] presented a case of a 33-year-old lady with progressive exertional dyspnea.

\section{Diagnostic Methods}

Ultrasound and fetal magnetic resonance imaging (MRI) help prenatal diagnosis of CLE and associated complications such as polyhydramnios and fetal hydrops [19]. Ultrasound may demonstrate gradual increase or decrease of the lesion echogenicity [20]. However, increased echogenicity of the lungs that could be too subtle to be appreciated in utero, affects prenatal ultrasound diagnosis of CLE [21].Fetal MRI should differentiate CLE from microcysticcongenital cystic adenomatoid malformation (CCAM) and bronchopulmonary sequestration because of the former's homogeneity and intact lung structure with stretched hilar vessels [22].It is important to continue postnatal investigations of prenatal ultrasound abnormalities even when they appear to have resolved [23].

Early neonatal diagnosis is crucial and in many cases is complicated due to the variety of its clinical presentation that varies from mild tachypnea to severe respiratory distress [19].Diagnosis is often confused with pneumonia and pneumothorax [24].A case of CLE with pneumothorax due to a large bulla in an adult has been reported [25].It is a significant risk during an aesthetic induction if undiagnosed preoperatively [26].

The differential diagnosis of CLE includes pneumothorax, cysts, and diaphragmatic hernia that can be ruled out by linear bronchovascular and alveolar markings on chest $\mathrm{x}$-ray. Other conditions need differential diagnosis include pulmonary sequestration, CCAM and upper airway obstruction that can be ruled out by ultrasonography, color doppler imaging and magnetic resonance imaging [27].

The initial diagnosisis carried by chest X-ray (Figure 1) and confirmed by computed tomography scan (Figure 2) and histopathological studies (Figure 3)[28].The typical chest $\mathrm{X}$ ray features include presence of bronchovascular markings with transillumination, and secondary compression of the over expanded lobe (tracheal or a mediastinal shift to the opposite side, atelectasis of the adjacent lobes or herniation of the expanded lobe across the midlines). A region of increased density rather than a hyperlucency may lead to a misleading diagnosis of pneumonia [29].

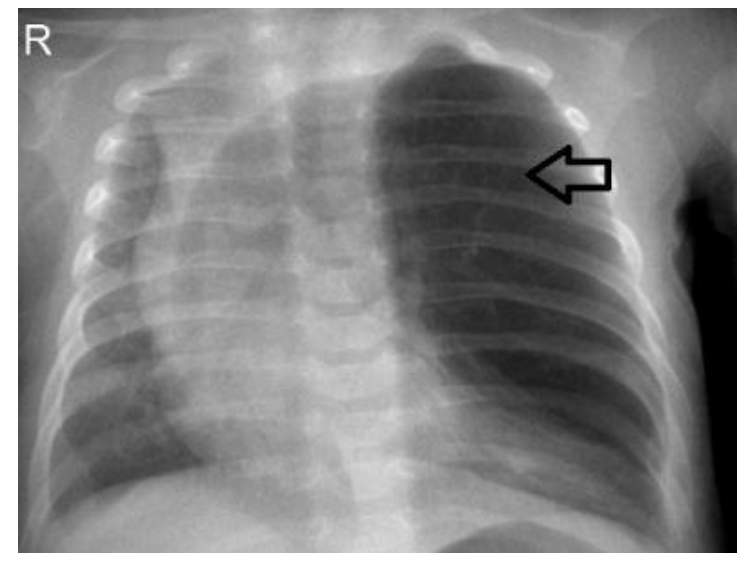

Fig1.Chest $X$-ray showing overexpandedhyperlucent left upper lobe (Arrow) with mediastinal shift. R: Right side.

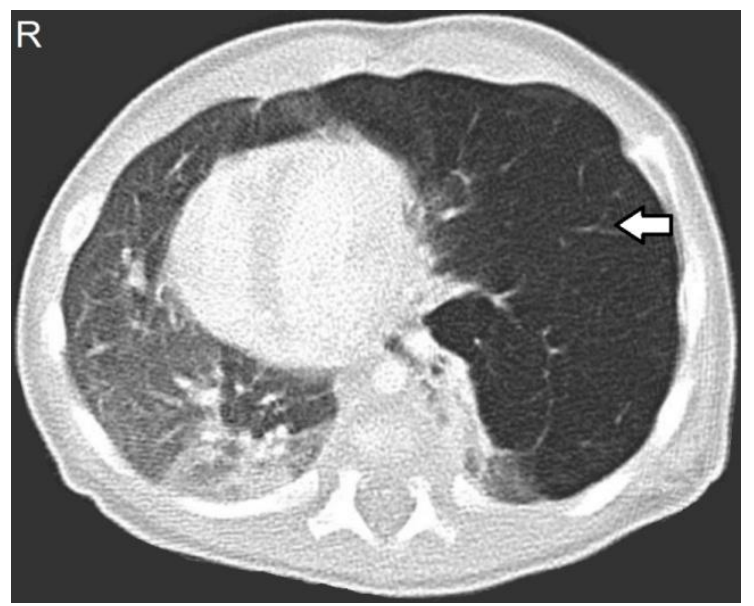

Fig.2. Chest computed tomography scan (lung window) showing congenital lobar emphysema of right middle-lobe (Arrow) compressing adjacent tissues with mediastinal shift. R: Right side.

Chest computed tomography (CT) has a definite role in early diagnosis with a special importance to avoid inadvertent chest tube insertion in such cystic lucent lung lesion on chest X-ray, and hence avoid associated complications [30]. Chest imaging with CT or MRI can save life of a neonate when there is a high suspicion of CLE. The non-improvement of the distress and nonexpansion of the lung in neonate presented with respiratory distress increases the suspicion of congenital lobar emphysema, and indicates chest CT or MRI [31]. 


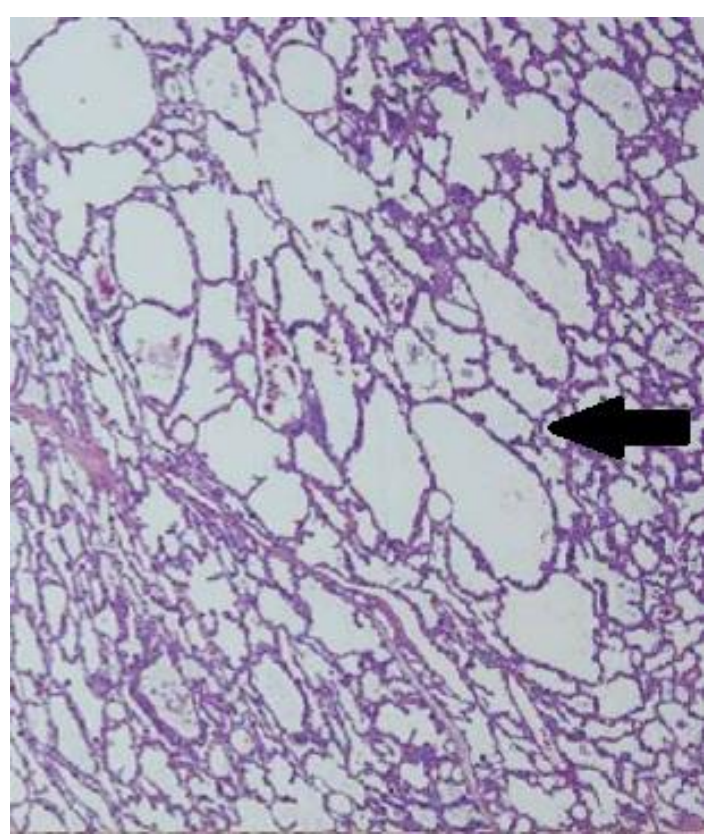

Fig3. Histopathological specimen of left upper lobe showing over distension of alveoli and thin interalveolar septa (Arrow).

Nuclear imaging by ventilation perfusion scanning(Figure 4) is useful to represent the reduced perfusion of affected lobe due to vessel compression and increased perfusion of normal lobes due to shunting [32].It is helpful in older patients with fewer symptoms to demonstrate the extent of surgical resection for segmental lobar involvement [33].

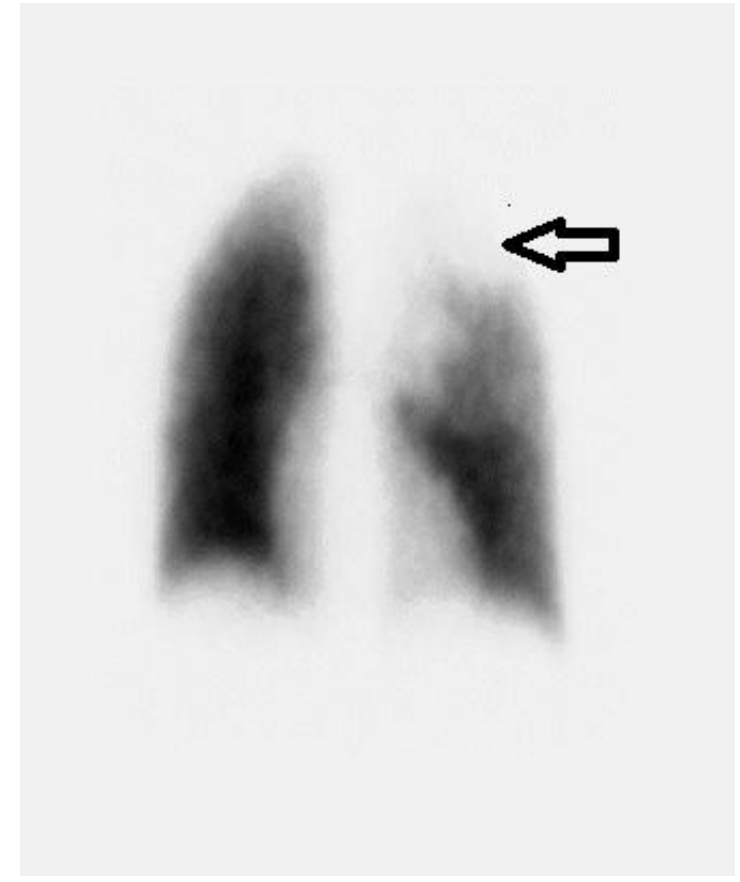

Fig4. Pulmonary ventilation perfusion scan showing reduced perfusion in left upper lobe (Arrow).

Bronchoscopy is useful in evaluating airway patency and dynamic changes in the airway, and in excluding obstruction by aspirated material or from external compression, but its routine use is often unnecessary. Flexible bronchoscopy is superior to rigid bronchoscopy in demonstrating dynamic changes in the airway [34, 35].

Multislice CT with reconstructions of the bronchial tree and virtual bronchoscopy are important imaging tools for differential diagnosis of CLE and bronchial foreign bodies, as both may present with pulmonary hyperinsuflation findings and nonspecific clinical features [36].Presence of other congenital cardiac malformations may require further echocardiographic evaluation and/or cardiac catheterization [37].

\subsection{Anesthetic Challenges}

Anesthetic management of a child with CLE is challenging. Precautions during induction of anesthesia and endotracheal intubation avoid further gas in the emphysematous lobes to prevent an increase of intra thoracic pressure, which further decreases the respiratory reserve. During induction, it is critical to avoid crying and struggling, and maintaining the airway pressure of $20-25 \mathrm{~cm}$ of $\mathrm{H}_{2} \mathrm{O}$ through gentle manual ventilation. In addition, it is important to reduce the time between anesthesia induction and thoracotomy $[38,39]$.

A debate surrounds optimal technique of ventilation. Advocates to avoid positive pressure ventilation is based on subsequent further inflation, thus, lung isolation or selective main stem bronchus intubation is desirable. The useful techniques of ventilation for resection of CLE include pressure regulated volume controlled (PRVC), high frequency ventilation, and pressure controlled ventilation keeping airway pressure below $20 \mathrm{~cm} \mathrm{H2Oto} \mathrm{control} \mathrm{the}$ delivered tidal volumes[40-42].

For a single stage excision of bilateral CLE, Iodice et al [43] suggested inhalational induction, maintained spontaneous ventilation with sevoflurane in $100 \%$ oxygen, and only instituted positive pressure ventilation after femoral and arterial line access. This allowed minimize the duration of positive pressure ventilation prior to surgical incision and reduce the potential for hyperinflation of the emphysematous lobes. This method may facilitate safe induction of anesthesia and establishment of invasive monitoring, avoid the potential for cardio respiratory compromise.

\subsection{Treatment}

Although surgery is the traditional routine management of congenital lobar emphysema, the contemporary management directs toward 
conservativenon-operative approach with follow-up in asymptomatic or mild symptomatic patients [44].Long-term evaluation of surgically and conservatively treated asymptomatic children showed no difference in lung growth which confirmed that asymptomatic or mild symptomatic patients do not benefit from surgical treatment [45]. The conservative management involvesclose follow-up of the children, alarming the family about the disease features [46].

Severe respiratory distress is the main indication for surgical excision. Evidence of mediastinal shift with subsequent compression of the unaffected lung lobes indicates surgical excision. Some surgeons recommended surgery in all infants younger than 2 months or older than 2 months with severe respiratory symptoms $[19,35]$.

The surgical options for treatment of CLE include lobectomy through thoracotomy or video-assisted lobectomy [47].Segmental resections of can be performed safely while conserving healthy lung tissue. In one study, median hospital stay was longer for the lobectomy at 7days when compared to the segmentectomy group at 2 days. There was not a difference in complication rate $(21 \%$ vs. $19 \%$, $\mathrm{p}=1)$ or in median number of chest tube days $(2$ vs. 3days, $\mathrm{p}=0.07$ ) for segmentectomy versus lobectomy patients [48].

Management of concomitant congenital heart disease (CHD) and CLE depends on severity of cardiac lesion and ease of management. In cases with high pulmonary artery pressure, the management is palliative or corrective surgery for CHD with lobectomy for CLE. Clinical follow-up of CHD is sufficient treatment after lobectomy for small lesion without high pulmonary artery pressure. When CLE is a result of compression associated with patent ductusarteriosus (PDA), ligation of PDA before lobectomy may be considered [37].

Video-assisted thoracoscopic surgery (VATS) is a serious alternative to traditional thoracotomy for children with CLE as it results in reduced length of postoperative period, lesser amount of complications and good cosmetic and functional results [49].Granato et al [50] reported first case of endoscopic parenchymal sparing resection in CLE carried out by 3-portal VATS using singlelung ventilation leading to precise determination the limit to resect due to the obvious and clear-cut distinction between functioning and non -functioning parenchyma of the lobe.
Surgically treated patients remain asymptomatic with normal growth and development. They may have abnormal postoperative pulmonary function tests [51], or have some compensatory growth of the remaining lung tissue which rule out functional impairment owing to loss of lung tissue or residual disease [52].

The contemporary reported unfavorable postoperative outcomes after surgical excision of CLE include death in up to $13 \%$ of cases, pneumothorax, delayed weight gain, permanent oxygen dependency, pneumonia, atelectasis, post-operative bleeding, and wound infection. The number of affected lobes and base deficit at the time of admission are associated with mortality [53, 54].

\section{CONCLUSions}

Congenital lobar emphysema is a rare and serious developmental malformation still with multiple controversial issues about its etiology, presentation, natural history, diagnostic workup, and treatment options. High index of suspicion and careful differential diagnosis help to save life of patients with CLE. Combination of clinical features, radiological characteristics, and histological abnormalities provides the appropriate diagnosis. Approach by multidisciplinary team of pediatrician, surgeon, radiologist, and anesthetist is important to obtain better outcome of such surgically correctable cause of neonatal respiratory distress. Surgical techniques to preserve more of healthy lung parenchyma and segmental resection need further evaluation.

\section{REFERENCES}

[1] Mendeloff EN. Sequestrations, congenital cystic adenomatoid malformations, and congenital lobar emphysema. Semin Thorac Cardiovasc Surg. 2004; 16(3): 209-14.

[2] Thakral CL, Maji DC, Sajwani MJ.Congenital lobar emphysema: experience with 21 cases. PediatrSurg Int. 2001: 17: 88-93.

[3] Latif I, Shamim S, Ali S. Congenital lobar emphysema. J Pak Med Assoc. 2016; 66(2): 2102.

[4] Abdellah O1, Mohamed H, Youssef B, Abdelhak B. A case of congenital lobar emphysema in the middle lobe.J ClinNeonatol. $2013 \mathrm{Jul} ; 2$ (3):135-7.

[5] Toyoshima M, Suda T, Chida K. Asymptomatic congenital lobar emphysema in a young adult. Intern Med. 2012;51(19):2839-40.

[6] Abushahin AM, Tuffaha AS, Khalil NK, Ismeal AM.Bilateral congenital lobar emphysema: A 
rare cause for respiratory distress in infancy. Ann Thorac Med. 2012 Oct;7(4):250-2.

[7] Pike D, Mohan S, Ma W, Lewis JF, Parraga G. Pulmonary imaging abnormalities in an adult case of congenital lobar emphysema. J Radiol Case Rep. 2015 Feb 28;9(2):9-15.

[8] Santra A, Dutta P, Manjhi R, Pothal S. Congenital lobar emphysema presenting at late childhood: A rare case report. Lung India. 2014 Jul;31(3):302-4.

[9] Kumar B, Agrawal LD, Sharma SB. Congenital bronchopulmonary malformations: a singlecenter experience and a review of literature. Ann Thorac Med. 2008 Oct; 3(4):135-9.

[10] Roberts PA, Holland AJ, Halliday RJ, Arbuckle SM, Cass DT. Congenital lobar emphysema: Like father, like son. J Pediatr Surg. 2002 May;37(5):799-801.

[11] Chinya A, Pandey PR, Sinha SK, Sarin YK.Congenital lobar emphysema: Pitfalls in diagnosis.Lung India. 2016 May-Jun;33(3): 317-9.

[12] Ogul H, Sevketbeyoglu H, Ozgokce M, Alper F. - Congenital lobar emphysema association with double superior vena cava and horseshoe kidney. Ann Thorac Surg. 2012;94:21-31.

[13] Choh NA, Choh SA, Jehangir M, et al. Congenital lobar emphysema associated with polysplenia syndrome. Ann Saudi Med. 2010;30:482-484.

[14] Tander B, Yalçin M, Yilmaz B, Ali Karadağ C, Bulut M. Congenital lobar emphysema: a clinicopathologic evaluation of 14 cases. Eur J Pediatr Surg. 2003;13(2):108-11.

[15] Peters RT, Burge DM, Marven SS. Congenital lung malformations: an ongoing controversy. Ann R CollSurg Engl. 2013; 95: 144-147.

[16] Prabhu M, Joseph TT. Congenital lobar emphysema: Challenges in diagnosis and ventilation.Anesth Essays Res. 2012 JulDec;6(2):203-6.

[17] Rusakow LS, Khare S. Radiographically occult congenital lobar emphysema presenting as unexplained neonatal tachypnea. PediatrPulmonol. 2001 Sep;32(3):246-9.

[18] Arnaud D, Varon J, Surani S. An Unusual Presentation of Congenital Lobar Emphysema. Case Rep Pulmonol. 2017;2017:6719617.

[19] Kanakis M, Petsios K, Bobos D, Sarafidis K, Nikopoulos S, Kyriakoulis K, Lioulias A, Giannopoulos N. Left Upper Lobectomy for Congenital Lobar Emphysema in a Low Weight Infant. Case Rep Surg. 2016;2016:4182741.

[20] Olutoye OO, Coleman BG, Hubbard AM et al. Prenatal diagnosis and management of congenital lobar emphysema. J Pediatr Surg. 2000;35:792-795.
[21] Quinton AE, Smoleniec JS. Congenital lobar emphysema-the disappearing chest mass: Antenatal ultrasound appearance. Ultrasound Obstet Gynecol. 2001;17:169-71.

[22] Liu YP, Shih SL. Congenital lobar emphysema: appearance on fetal MRI.PediatrRadiol. 2008 Nov;38(11):1264.

[23] Quinton AE, Smoleniec JS. Congenital lobar emphysema--the disappearing chest mass: antenatal ultrasound appearance. Ultrasound Obstet Gynecol. 2001;17(2):169-71.

[24] Prabhu M, Joseph TT. Congenital lobar emphysema: Challenges in diagnosis and ventilation.Anesth Essays Res. 2012 Jul-Dec; 6(2):203-6.

[25] Muramatsu T, Furuichi M, Nishii T, Ishimoto S, Shiono M. Lobar emphysema with pneumothorax in an adult: report of a case. Surg Today. 2013 May;43(5):539-41.

[26] Mulvany JJ, Weatherall A, Charlton A, Selvadurai H. Congenital lobar emphysema: diagnostic and therapeutic challenges. BMJ Case Rep. 2016;2016. pii: bcr2016214994.

[27] Quinton AE, Smoleniec JS. Congenital lobar emphysema-the disappearing chest mass: Antenatal ultrasound appearance. Ultrasound Obstet Gynecol. 2001;17:169-71.

[28] Abdellah O, Mohamed H, Youssef B, Abdelhak B. A case of congenital lobar emphysema in the middle lobe.J ClinNeonatol. 2013;2(3):135-7.

[29] Kumar S, Debata PK, Gupta R. Congenital lobar emphysema and intercostal drainage tube insertion: the common fate of an uncommon disease. J ClinDiagn Res. 2012;6(9):1568-70.

[30] Prabhu SM, Choudhury SR, Solanki RS, Shetty GS, Agarwala S. Inadvertent chest tube insertion in congenital cystic adenomatoid malformation and congenital lobar emphysemahighlighting an important problem. Indian $\mathbf{J}$ Radiol Imaging. 2013 Jan;23(1):8-14.

[31] Kumar S, Debata PK, Gupta R. Congenital lobar emphysema and intercostal drainage tube insertion: the common fate of an uncommon disease. J ClinDiagn Res. 2012 Nov;6(9):156870.

[32] Prabhu M, Joseph TT. Congenital lobar emphysema: Challenges in diagnosis and ventilation. Anesth Essays Res. 2012;6(2):2036.

[33] Padilla L, Orzel JA, Kreins CM, Weiland FL. Congenital lobar emphysema: segmental lobar involvement demonstrated on ventilation perfusion imaging. J Nucl Med 1985; 26: 1343-1344.

[34] Ozçelik U, Göçmen A, Kiper N, Doğru D, Dilber E, Yalçin EG. Congenital lobar emphysema: evaluation and long-term followup of thirty cases at a single center. PediatrPulmonol. 2003;35(5):384-91. 
[35] Andrade CF, da Costa Ferreira HP, Fischer GB. Congenital lung malformations. J Bras Pneumol. 2011;37(2):259-271.

[36] Hochhegger B, Irion KL, Andrade CF, Zanetti G, Marchiori E. Congenital lobar emphysema: the role of multislice computed tomography with virtual bronchoscopy in the differential diagnosis with bronchial foreign bodies. Eur Arch Otorhinolaryngol. 2012 Aug; 269(8): 2015-6.

[37] Dogan R, Dogan OF, Yilmaz M, Demircin M, Pasaoglu I, Kiper N, Ozcelik U, Boke E. Surgical management of infants with congenital lobar emphysema and concomitant congenital heart disease. Heart Surg Forum. 2004;7(6):E644-9.

[38] Nandihalli MC, Thammaiah SH, Kotekar N, Putran PR. Congenital lobar emphysema: A modified approach to anesthetic management. Indian J Crit Care Med. 2015;19(1):47-9.

[39] Celik M, Dostbil A, Aksoy M, Alici HA, Dogan N, Ince I, Aydin Y, Ahiskalioglu A. Anesthetic Management in Children with Congenital Lobar Emphysema.ActaChir Belg. 2015;115(4):279-83.

[40] Tempe DK, Virmani S, Javetkar S, Banerjee A, Puri SK, Datt V. Congenital lobar emphysema: Pitfalls and management. Ann Cardiac Anesth. 2010;13:53-8.

[41] Goto H, Boozalis ST, Benson KT, Arakawa K. High frequency jet ventilation for resection of congenital lobar emphysema. AnesthAnalg. 1987;66:684-6.

[42] Prabhu M, Joseph TT. Congenital lobar emphysema: Challenges in diagnosis and ventilation. Anesth Essays Res. 2012;6(2):2036.

[43] Iodice F, Harban F, Walker I. Anesthetic management of a patient with bilateral congenital lobar emphysema. PaediatrAnaesth. 2008 Apr;18(4):340-1.

[44] Ceran S, Altuntas B, Sunam GS, Bulut I. Congenital lobar emphysema: is surgery routinely necessary? Afr J Paediatr Surg. 2010 Jan-Apr;7 (1):36-7.

[45] Eigen H, Lemen RJ, Waring WW. Congenital lobar emphysema: long-term evaluation of surgically and conservatively treated children. Am Rev Respir Dis. 1976 Jun;113(6):823-31.

[46] Karnak I, Senocak ME, Ciftci AO, Büyükpamukçu N. Congenital lobar emphysema: diagnostic and therapeutic considerations. J Pediatr Surg. 1999 Sep;34(9):1347-51.

[47] Gluer S, Reismann M, Ure BM. Congenital lobar emphysema. Ann Thorac Surg. 2008;85(2):665.

[48] Bagrodia N, Cassel S, Liao J, Pitcher G, Shilyansky J. Segmental resection for the treatment of congenital pulmonary malformations. J Pediatr Surg. 2014 Jun; 49(6): 905-9. doi: 10.1016/j.jpedsurg. 2014.01. 021.

[49] Rqzumovskiı̌AIu, Geras'kin AV, Sharipov AM, Bataev SK, Kulikova NV, Zadverniuk AS, Stepanenko NS. The surgical treatment of the inborn lobar emphysema in children: the comparative analysis. Khirurgiia (Mosk). 2011; (11):45-51

[50] Granato F, Voltolini L, Spina D, Paladini P, Gallazzi M, Gotti G. VATS for congenital lobar emphysema: a case report. Minerva Chir. 2009; 64(1):111-5.

[51] Suryawanshi K, Nikumbh D, Singhavi S, Damle R, Dravid N. Congenital Lobar Emphysema with Pulmonary Extramedullary Hematopoiesis. Turk PatolojiDerg. 2017; 33(1):74-76.

[52] Frenckner B, Freyschuss U. Pulmonary function after lobectomy for congenital lobar emphysema and congenital cystic adenomatoid malformation. A follow-up study. Scand J ThoracCardiovasc Surg. 1982;16(3):293-8.

[53] Nazem M, Hosseinpour M. Evaluation of early and late complications in patients with congenital lobar emphysema: a 12 year experience. Afr J Paediatr Surg. 2010;7(3):1446.

[54] Karunasumetta C, Kuptarnond C, Prathanee S, Intanoo W, Wongbuddha C. Surgical outcomes for congenital lung malformations: 10 yearsexperience at a single center. J Med Assoc Thai. 2014;97(1):52-9.

Citation: Yasser Ali Kamal. Management of Congenital Lobar Emphysema: The Current Challenges. ARC Journal of Surgery.2018; 4(1):20-25. doi: dx.doi.org/ 10.20431/2455-572X. 0401005.

Copyright: (C) 2018 Authors. This is an open-access article distributed under the terms of the Creative Commons Attribution License, which permits unrestricted use, distribution, and reproduction in any medium, provided the original author and source are credited. 